\title{
Progamme Planning in Extension System, an Effective tool for Rural Development Project in Nigeria
}

\author{
Udemezue JC* \\ National Root Crops Research Institute, Nigeria \\ *Corresponding author: Udemezue JC, National Root Crops Research Institute, Umudike, Nigeria

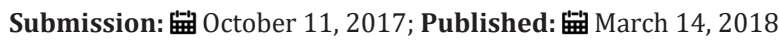

\begin{abstract}
To maintain the trends of agricultural development in any country, there is need to sensitize and incorporate the rural farmers who are responsible for about $80 \%$ of agricultural production in programme planning and development, and when these rural farmers are involved in programme planning and development. This implies that the beneficiaries of programmes should be adequately and practically involve in various levels of planning and implementation of the planning. When this is done, the target is not only in economic growth, increased production, greater efficiency and effectiveness of the programme, but also to welfare issues about equity and poverty reduction.

Therefore, in programme planning that concerns rural people, bottom-up approach is likely more effective than top-down approach and these can as well achieve better results than the opposite, since everybody has sense of belonging and participation. In the light of the above, the author used the available literatures to review the following issues; Agricultural extension programme, programme, who is a programmer planning. Resources, programme planning in extension, importance of programme planning in extension, project, rural development, monitoring and evaluation, similarities between monitoring and evaluation, difference between monitoring and evaluation, monitoring indicators, the main players in evaluation, the four elements of evaluation ,the various approach used in programme planning/development, work plan and calendar of work in extension programme.

This paper therefore recommends that the extension workers who are the key players in information dissemination to farmers should know the various approach used in programme planning and development. Government in all sectors should organize work shop for workers as regards to progamme planning/development just to make work effective and functional and the knowledge of monitoring and evaluation should be kept abreast with extension workers and other government staff for effective delivering job.
\end{abstract}

Keywords: Programme planning and development; Monitoring and evaluation

\section{Introduction}

The role of agriculture resources to bring about economic growth and sustainable development of a nation cannot be overlooked and underestimated in our contemporary society. Agriculture contributes to the growth of the economy, provides employment opportunities for the teaming population, export revenue earnings and eradicate poverty in the country [1]. According to [2], the need to plan for rural and agricultural development in the developing world is very important. In Africa, about $70 \%$ of the population lives in the rural areas and up to $90 \%$ of this population is engaged in Agriculture for their livelihood, in Nigeria, about $80 \%$ of the population in the country comes from the subsistent resource poor farmers who live in the rural areas and this could be the reason World bank said that comprehensive rural development must be a central component of any strategy to achieve poverty reduction objective [3].

Therefore, to maintain the trends of agricultural development in any country, there is need to sensitize and incorporate the rural farmers who are responsible for about $80 \%$ of agricultural production in programme planning and development and when these rural farmers are involved in programme planning and development. They will have the opportunity to contribute effectively against the failure of the programme because "the few" among them may not want to be part of the failure of their programme. Many programme have been initiated by government to develop rural areas, but some of these programmes became still bore and abortive due to one reason or the other.

In Nigeria, we have had programmes like: Operation Feed the Nation (OFN), Green Revolution, Agricultural Development Project (ADP), FadamaI, II, III, among others, yet, these progammes have not succeeded in developing the rural areas and significantly improving our agricultural production, because the planning procedure has been largely defective. However, the intended beneficiaries of the planned programmes have not been involved in the planning. Programmes have been developed without a proper 
understanding of the needs and aspirations of the people for whom the programmes are planned for and as a result of this; some of the programmes became moribund and inoperative along the line. Therefore, sense of belonging is a key to success for programme planning and development.

According to [2], The National Housing Scheme of the Federal Government between 1983 and 1986 did not achieve result because the beneficiaries were not consulted, they were not involved in the designing and building of the house projects, and the scheme did not also address the felt needs of the people. Hence, the scheme was automatically rejected by the majority of the people in the Northern part of Nigeria. Therefore, in designing programmes, there is need to change our attitude from "top-down" to "bottom-up" planning just as to address the felt needs of the beneficiaries. This implies that the beneficiaries of programmes should be adequately and practically involve in various levels of planning and implementation of the planning.

When this is done, the target is not only in economic growth, increased production, greater efficiency and effectiveness of the programme, but also to welfare issues about equity and poverty reduction. Therefore, in programme planning that concerns rural people, bottom-up approach is likely more effective than top-down approach and these can as well achieve better results than the opposite, since everybody has sense of belonging and participation.

\section{Terminologies Used In Programme Planning}

In order to keep the readers abreast with some concepts and terminologies used in programme planning, this paper therefore, selected some concepts and terminologies that may create distortion in the minds of the readers and did needful to their explanation. They are as thus; Agricultural Extension Programme (AEP), a programmer, Extension Programme Planning (EPP), monitoring and evaluation in agricultural extension programme, Project, rural development, planning and resources.

\section{Planning}

According to [4], "planning" means "thinking carefully about something you want to do and decide how and when you will do it". What can be lifted from this definition is that planning is setting up one's mind in something or a project one wants to do, and choose how, where, what and when to do it. Dictionary.com, also defined planning as "a scheme, programme or method worked out before hand for the accomplishment of an objective". We learned from this definition that planning is a set of activities put together to solve a particular problem. Hence, planning is a problem (objective) solving activity. Planning is created because there is an existing problem or expected target which needs to sort out through effective planning.

Therefore, there will be no planning if there is no existing problem or target to be handled with planning scheme. [2] is of the opinion that planning is a "precise forecast of events so that an external hand can intervene to assume meeting of the exogenously determined target". This definition means that planning is a clear cut document that defines every activity, including how it will be done and what it will cost to get it done. In this point, the planned document is so clear that a donor agency can pick up the paper and know exactly what to do. This brings planning to the simplest definition as "as outline of what to do to achieve a set objective". Therefore, planning is an itemization of what intends or intended to do to actualize a predetermined objective.

\section{Resource}

Resource could be seen as all the money, property and skills, among others that are available to carry out a project over a period of time. However, it is an economic productive factor requires accomplishing an activity or as means to undertake an enterprise and achieve desired result. Resource is a service or other asset used to produce goods and services that meet human needs and wants. On the other hand, a resource could be a person, asset, material or capital which can be used to accomplish a goal. Land, labour and capital are the most basic resource. Every project needs financial and material resources for effective extension. Financial resources are the most important subsystem for the success of any project. Therefore, when planning, adequate consideration must be given to where the funds will come from and how adequate the funding will be. More so, the opinion of the funding agency must or should be put into consideration, when planning for a project, otherwise, such a project may be starved of the needed funds.

\section{Programme}

A programme is a set of sequential operation for implementing a scheme for development. Therefore, a programme is a set up scheme usually designed for the welfare of the people and development through effective planning and implementation. It is a set of planned activity to bring about development and when these activities become an action of intent by the government or agency, it becomes a programme. There are a lot of rural and agricultural development programmes in Nigeria: it is a plan with a series of actions which are designed to achieve something important.

\section{A Programmer}

According to [5], a programmer in agricultural extension is an individual who provides leadership and performs tasks that are related to planning, organizing, teaching and evaluating continuing educational extension programme. It requires skills, knowledge, imagination and reasoning abilities. It is a person who provides services to people through planning, organizing, teaching and evaluation of extension programme with a view of impacting changes into the skill, knowledge and attitude of the farmers. Good programme planning requires the ability to synthesize facts and value judgments, in a process of sound decision making about the objectives

Planning of extension programme should be based on existing facts rather than imaginations. Therefore, the ability of a programmer to programme effectively requires (a) an in-depth knowledge of the nature and function of planning (b) skills in formulating procedure (c) skills in identifying problems and needs, (d) ability to decide the objectives and goals (e) skills in formulating means of course 
of action (f) skills in involving key leaders in the planning process. In view of these, it is a well known fact that effective programme planning is an intellectual activity that involves the study and use of facts and principles to attain objectives.

\section{Programme Planning in Extension}

This could be seen as a judicious effort to apply resources at the capacity/will of extension personnel and extension organization, including the skills, ability and knowledge acquired in the system to achieve the ultimate results that could help to improve agriculture and farmers to the greater levels of productivity. The operative term here is planning that may be described simply as studying the present in order to forecast the future. However, it is always to know what goals should be achieved, what need to be done to achieve them, why these things should be done, who should do them, where, when and how they should be done [6]. In agricultural extension, the terms programme planning and development are in extricable intertwine, which means that they could be used interchangeably. Programme development is applied to describe its actual programme planning process while planning can be seen as an approach to problem solving. Planning provides a systematic way of viewing problems and development short and long term solution. It could also be seen as a decision-making process used to help guide decisions concerning future needs. No extension activity is planned in isolation, every demonstration; public meeting or film show is part of an overall extension programme which an extension agent and farmers work towards agricultural development. Therefore, all extension activities require careful planning, if they are to be effective.

Hence, extension programme is a written document/statement that encompasses, objectives which the extension agent expects to be achieved in the area within a specific period of time, means of achieving these objectives, resources that are needed to accomplish the programme and the work plan indicating the schedule of extension activities that will lead to the achievement of the programme objective. It is a written statement that provides the essential framework within which the organization and its staff operate.

\section{Project}

Project and programme in the minds of some people seem to be the same thing but they are not. Although, sometimes they can be used interchangeably but they are two different words with relation. A project is a specific activities designed to accomplish part of a programme. This implies that project is a sub set of a programme and is usually location specific and designed to last within a given space of time. For instance, in a rural development programme, there will be different components like agricultural development, provision of roads and educational facilities. Each of these components of rural development becomes a project. More so, there are different types of project which can be under a programme and such projects can be experimental, demonstration, production project among others.

\section{Rural Development}

Rural development is a multi-sectoral activities supporting and promoting positive change in the rural areas [2]. The main aim of rural development is the improvement of material and social welfare of the people. Development in agriculture is seen as synonymous with rural development because since about $90 \%$ of rural dwellers are engaged in agricultural practices as their major source of income, this implies that rural areas cannot attain development without its agriculture being developed. However, agricultural development is not only increasing the productivity of the farmers alone but also it considers all the social welfare needed as a human being. Therefore, democracy is said to be incompetent once its dividend is not feasible and perceived by the rural people. Environment is man's first right, because whatever affects environment indirectly affects man directly. For these, there is need to save rural environment through development. So, rural development is taken as an integrated approach to improve the environment and wellbeing of the inhabitants of the community.

\section{Evaluation}

Evaluation is the systematic review and assessment of the benefits, quality and value of a programme or activity. It is an activity we get engaged in everyday because we are always making judgment relating to the value or worth of things we do or experience [5]. However, evaluation can focus on programme design, implementation and result. A good evaluation report gives information about the two facts:

(a) Is the programme doing what it does well?

(b) Is the programme doing the right things, in order to meet its programme objective?

Therefore, programme evaluation is the actual judgment passed on a programme following the results of measurement and assessment of the programme. One important point is that evaluation should determine the efficiency and capacity of the project during and after the completion of the project. Evaluation is the assessment of project/activities with the view to knowing whether the project/activity fulfils the objective that is set out to achieve. It is designed to provide systematically reliable and valid information on the product, impact and effectiveness of projects [7].

Evaluation is an instrument of decision making which helps us think through alternative means and choose those options that confirm best to the aims and are likely to achieve them most effectively. Hence, agricultural extension program evaluation is the process of delineating, collecting and providing information useful for judging decision alternative. Evaluation undertaken during project implementation and operation is usually referred to as "ongoing evaluation" while that carried out after project completion is known as ex-post evaluation. According to [6] for basic questions are required in evaluation

(a) What should be evaluated? 
(b) When should evaluation be carried out?, who should evaluate? And what are the steps to follow?

\section{Monitoring}

Monitoring is the careful watching and checking of an activity/ project in order to ascertain the performance of the project over a period of time. In agricultural extension, monitoring is continuous or periodic surveillance over the implementation of a project to ensure that input deliveries, work schedules, target outputs and other required actions are proceeding according to what has been planned [8]. Monitoring tells us whether project inputs are being delivered, are being used as intended and are having the initial effects as planned. However, monitoring uses baseline information collected during the design and preparation phase of the project and continues throughout the project lifetime when it compares actual inputs, outputs and activities with expected results. It alerts project management and policy-making about the potential problems that are likely to occur which may require urgent and timely corrective actions.

Table 1: Differences between Monitoring and Evaluation.

\begin{tabular}{|c|c|c|}
\hline S.No & Monitoring & Evaluation \\
\hline 1 & It is not scientific. & It is scientific. \\
\hline 2 & Monitoring does not involve collection of baseline or data bench. & It involves collection of baseline or bench mark data. \\
\hline 3 & $\begin{array}{l}\text { It studies how routine training and visits by staff are carried out and } \\
\text { visits by extension staff. }\end{array}$ & It does not study how routine training extensions are carried out \\
\hline 4 & It do not assess the overall effects and impact of programme. & It assesses the overall effects and impacts of program. \\
\hline 5 & $\begin{array}{c}\text { It does not assess the social, economic, attitudinal and situation } \\
\text { consequences of programme. }\end{array}$ & $\begin{array}{l}\text { It assesses or measures social, economic, attitudinal and } \\
\text { institutional consequences of programme. }\end{array}$ \\
\hline 6 & $\begin{array}{l}\text { Sources of information are mainly periodic and observation's } \\
\text { participant. }\end{array}$ & $\begin{array}{c}\text { It involves indepth studies, administrative reports, observations } \\
\text { and sample survey. }\end{array}$ \\
\hline 7 & $\begin{array}{l}\text { Reports are made to the project managers, the funding agencies, } \\
\text { management and policymakers. }\end{array}$ & Reports are made to the project supervisors, and beneficiaries. \\
\hline 8 & Conducted mostly during implementation. & Conducted both during and after implementation. \\
\hline
\end{tabular}

Planning helps us to decide what that contribution should be and how to achieve it while Evaluation enables us to judge whether we have had the impact we planned, contributed to changing the situation we wanted to change and whether or not we achieved our goal. According to [9], the difference between planning and evaluation could be explained using Planning-Evaluation Cycle. Often, evaluation is construed as part of a larger managerial or administrative process. Sometimes this is referred to as the planning-evaluation cycle. The distinctions between planning and evaluation are not always clear; this cycle is described in many different ways with various phases claimed by both planners and evaluators.

Usually, the first stage of such a cycle-the planning phaseis designed to elaborate a set of potential actions, programs, or technologies, and select the best for implementation. Depending on the organization and the problem being addressed, a planning process could involve any or all of these stages: the formulation of the problem, issue, or concern; the broad conceptualization of

\section{Similarities between Monitoring and Evaluation}

According to [5], monitoring and evaluation has the following similarities;

1. They are both indispensible tools for analyzing data, producing information for decision makers both within and outside the organization.

2. They are both conducted during implementation of programme.

3. They are both aimed at improving the efficiency of extension organization.

4. Monitoring and evaluation help in suggesting measures to correct deviation from plan during implementation.

5. Both monitoring and evaluation check the performance of the programme in question.

6. They conduct through investigation and adequate surveillance on programme/project (Table 1). the major alternatives that might be considered; the detailing of these alternatives and their potential implications; the evaluation of the alternatives and the selection of the best one; and the implementation of the selected alternative.

Although these stages are traditionally considered planning, there is a lot of evaluation work involved. Evaluators are trained in needs assessment, they use methodologies-like the concept mapping one presented later-that help in conceptualization and detailing, and they have the skills to help assess alternatives and make a choice of the best one. The evaluation phase also involves a sequence of stages that typically includes: the formulation of the major objectives, goals, and hypotheses of the program or technology; the conceptualization and operationalization of the major components of the evaluation -- the program, participants, setting, and measures; the design of the evaluation, detailing how these components will be coordinated; the analysis of the information, both qualitative and quantitative; and the utilization of the evaluation results (Figure 1). 


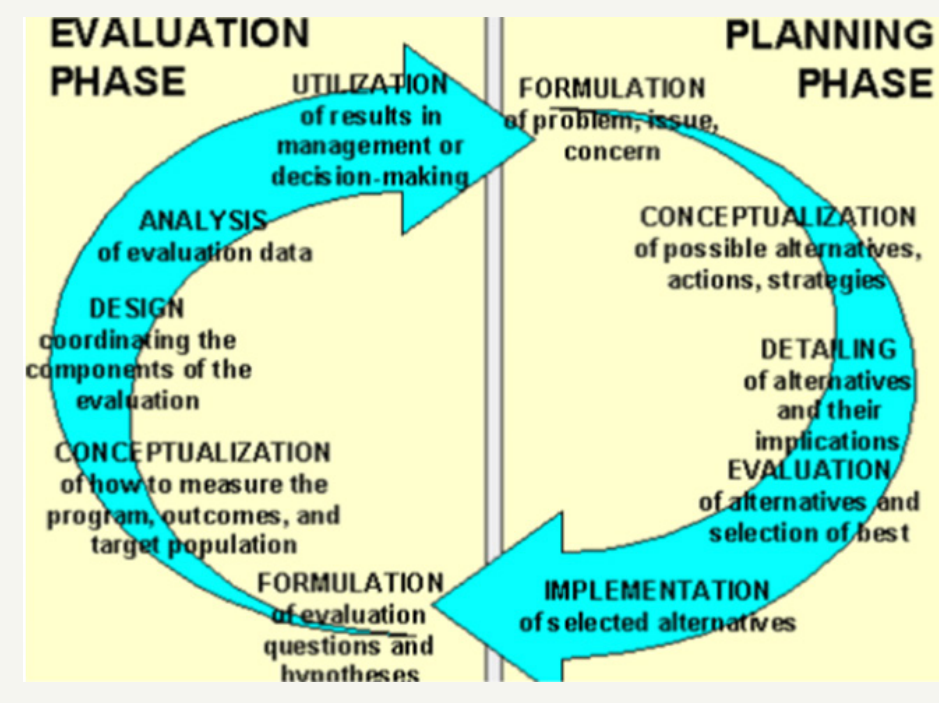

Figure 1: Planning-evaluation cycle.

\section{Levels of evaluation in extension programmes}

There are several levels of evaluation of extension programmes. At the most general level, the effect of extension on agricultural production, family incomes and standards of living can be evaluated. An increase in family living standards is usually an important ultimate goal of rural extension and it is, therefore, important to ask whether any increase has occurred. Evaluation of this kind involves measuring production and farm income for a representative sample of farm families, and then comparing the figures with previous levels. The changes revealed by these figures are then related to the extension inputs and activities during the programme.

However, extension is not the only factor that leads to higher production and living standards; changes in prices and in the availability of inputs are two of the many additional factors that affect the level of crop and of livestock production. Separating the effects of these various factors is a complex task and best left to specialist research and evaluation staff. Nevertheless, the agent should be aware of these economic changes and regularly ask himself how much his extension activities are contributing to the economic well-being of farmers and their families. He should also observe who is benefiting from extension. Is a broad cross-section of the farming population sharing the benefits, for example, or do one or two particular groups benefit most? An intermediate level of evaluation is provided by the extension programme itself.

Two questions are important here. Did the extension activities take place in the planned sequence and at the right time? Did these activities lead to the expected results? If the answers are negative, the agent should try to understand why. Perhaps he was overambitious about how many extension activities he could undertake, or maybe he did not receive the support he needed from other agencies. Whatever the reason, the agent will be able to learn from the evaluation process. He should be able to make more realistic plans in the future to ensure that the necessary support and inputs are provided.
Finally, the agent can evaluate at the level of each extension activity. All extension activities, such as demonstrations, talks or meetings with a farmers' group, have a purpose. The agent should try to check, wherever possible, not only how well the activity itself was conducted but whether the purpose was achieved. This will usually involve finding out whether the extension activity led to any changes in one or more of the following:- awareness of a particular idea, possibility or problem;- motivation to act in a particular way;knowledge about new farming practices;- skills needed to adopt a new practice;- behavior by farmers and their families (such as new farming methods), or by an extension group (such as making an application for funds to carry out a group project or the preparation of a formal group constitution).

At all levels of evaluation, the agent needs to collect information to compare the situation after the activity with the situation existing before. He will already have assessed the situation before evaluation when deciding on the need for the extension activity. When planning a result demonstration, for example, he will have some idea of how many farmers in the area know about, are interested in, or have already adopted the particular practice that is to be demonstrated. However, he can obtain a more accurate assessment by asking those who attend the demonstration how much they already know and what experience they have had of the practice. By carrying out a similar assessment after the demonstration, he can collect the information he needs for evaluation.

Some effects can be assessed much sooner than others. Immediately after a public meeting, for example, the agent can talk to a few members of the audience and check how clearly they understood what he was saying. Changes in behavior, on the other hand, will not happen at once and the agent must wait before checking these. There are several ways of collecting information for evaluation at the village level.

Agent's reports: Whether or not a formal report of each extension activity is required from agents by their extension officers, the agent should make some notes on each activity for his 
own use, concentrating on his conduct of the activity and on points to note for future occasions.

Supervisors: It is not easy for an agent to assess how well he conducts an extension activity; in particular, he cannot see himself through the eyes of the farmers who attend. It is useful, therefore, to have constructive comments from a supervisor or colleague.

Discussions: Informal discussion with farmers after the extension activity will reveal their immediate reactions. It is often useful to record such discussions using a tape recorder for later transcription and fuller analysis.

Questionnaires: Simple check-lists and questionnaires can be used when the agent has the time and opportunity to carry out a more formal evaluation of extension activities. Before a result demonstration on early planting, for example, the agent could prepare a list of four or five important facts that farmers should know after they have attended. By asking a sample of farmer's questions on the facts, before and after the demonstration, the agent can assess its impact on farmers' knowledge.

Observation: Where changes in farming practice are concerned, observation is an accurate source of information. The agent can see whether or not his advice is being adopted on farms in the area. Many extension organizations have their own formal procedures for evaluation. In some, the agent prepares a detailed plan of work each month on a standard form, showing what he plans to do each day during the month and how these activities fit in with his annual extension programme. The plan of work is then used as the basis for evaluation at the end of the month.

Did he do all that he planned? Did he encounter any problems that he should take into account in the future? Is he on target in terms of progress toward his annual extension programme objectives? This procedure may be combined with a monthly meeting of agents in a particular district at which progress and problems in each area are discussed. Whatever the formal procedures in a particular organization, however, the agent should think of evaluation as an attitude of mind. He should develop a readiness to ask what happened, why it happened and how it could be done better in the future. In this way, he will continue to learn and improve his extension work.

\section{Why do we evaluate and who should evaluate?}

It is very important and of beneficial to know why we evaluate and who should evaluate a particular programme for effectiveness. In programme planning, it does not serve well to bring a person outside the programme to assess the effectiveness of the programme because he/she may lack an in depth knowledge of the programme. Therefore, the person who is responsible for providing leadership in planning and development of a programme should be responsible for its evaluation. In a nut shell, agricultural extension administrator and his workers should evaluate their own programme because the process itself provides a useful learning experience that improves their knowledge, helps them to gather useful evidences which could help in programme implementation and helps them also to grow professionally because we used to say that practice makes perfect. In view of these, [5] saw the followings as the important of evaluation;

a) We learn about our clientele and their situation from evaluation.

b) It helps to concentrate on goals/objectives.

c) Extension agents gain satisfaction and sense of accomplishment by knowing the extent of achievement.

d) Evaluation process makes it necessary to state clearly, the objective of the programme.

e) It gives room for effective planning and execution of programme.

f) Evaluation serves as public relations. It provides objective evidences and reliable information to be given to the public on progress and justifies financial support.

g) Evaluation shows the strength and weakness of a programme thereby helping in the improvement of the programme.

h) It is an eye-opener to the extension agent. It provides a critical view of the on-going programme and makes the extension agent to be aware of the need for improvement and adjustment where needed.

\section{Monitoring Indications}

In project monitoring, there are some basic variables to be monitored and those variables are called monitoring indications: they are as follows:

a) Project Inputs: These are the resources such as capital, manpower, goals, services, training and techniques required by any project to assist the farmers in achieving the pre-determined objective.

b) Project Outputs: These are the physical outcomes such as quantity of seeds, fertilizers, herbicides used and the percentage of the farmers who used them to achieve the desired goals/objectives.

c) Project Effects: These are the effects of the project output of the farmers (from 1-3 years of establishing the project). These include; increase in yields, purchasing of better seeds, fertilizers and equipment, use of health facilities, improved transportation, availability of drinkable water and credit facilities among others.

d) Project Impact: These are the changes that have resulted from the project inputs, outputs and effects. They include increase in farmers' income, acquiring of better social status, changes in knowledge, attitude, skill and aspiration and general better standard of living. Therefore, impact can take up 5-10 years for its validity [9].

\section{Four elements of Evaluation}

\section{Objective}

Objective could be defined as the end towards which our efforts 
are directed. It is a statement of direction of movement.

\section{Criteria}

A criterion could be a rule, standard, norm, behavior, or conditions that could be applied in any value judgment. However, it could be seen as the acceptable or ideal behavior against which value judgment is made. Therefore, criteria are the measures or indicators against which something could be judged.

\section{Evidences}

Evidences involve the process of seeking facts or information with respect to the impacts of a given programme in a given area based on the programme predermined objectives. They involve going into the field to gather necessary information from a given sample, tabulation and analysis of findings and discussion of results for necessary value judgment. The quality of evidences obtained is a function of the knowledge of the study area, the medium through which the data are analyzed, the achievability of the behaviors or characteristics on which the evidence is based and timing of data collection for example, family size, farm size, yield and level of income [5].

\section{Judgments}

A judgment could be seen as an opinion formed especially after thinking carefully about something else or an ability to make sensible decisions about what to do and when to do it over a period of time. In agricultural extension terminology, it could be referred to as the final statement or conclusion based on the ability and act of a programme after implementation. Judgment is the process of assigning values to the myriad of alternatives derived from the evidence. It is important to note that judgment should not be made in a vacuum or isolation of the predetermined objectives. The real should be compared with the ideal. Judgment requires wisdom, vision, impartiality, scope and depth. As a matter of this, the soundness of an evaluation is a function of the accuracy and adequacy of the judgment made. Hence, judgment could be influenced by the types of information gathered and the attitude of the Judge in question. Diagrammatically, the relationship between objectives, criteria, evidences and judgment could be represented in a lineal model as follows:

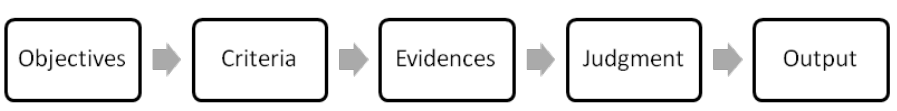

Here, the output of evaluation will tell whether the objectives of the programme is achieved or not and this will ensure the feasibility of the programme into the lives of the communities involved. Sometimes, this output could be seen as a result because it determines the continuity of a programme over a period of time.

\section{Agricultural Extension Programme}

According to [6], it involves making of a list of activities, situations, needs, problems, solutions and priorities, and who is to do what, when, where and how?. On the other hand, [10] perceived agricultural extension programme as a written, long-range and annual working plan with specific objectives for agricultural development of an area by its community, assisted and guided very closely by trained and experienced local extension workers. In an extension to this, it is a direction of movement and statement of all predetermined actions or products to be reached through educational means. The statement includes how objectives are to be met through setting-up of teaching situations to change people's knowledge, skills and attitude [5]. Therefore, agricultural extension programme could be seen as a well packaged written calendar of work with clearly defined objectives and farmer's felt needs that could be attained through setting-up teaching situations to change people's knowledge, skills and attitude. This shows how the extension and when, where and how scheduled extension activities will take place. In this case, programme is developed by putting the work plan into effect. Monitoring and evaluation of the programme is periodically done in order to attain the programme objectives and needs of the people involved in the programme. This will in turn increase farmers' aspiration as well as their living standard. Therefore, agricultural extension programme is a programme designed specifically to improve the livelihood of the rural farmers.

\section{Importance of programme planning in extension}

The task of every extension worker is to update farmers' knowledge on a better farming system to improve their standard of living and other related needs through effective teaching of programme planning. Effective teaching is the result of careful planning and not chance. However, since extension programme comprises series of teaching activities, planning is important. In view of these, [5] enumerated the following as the need for programme planning in extension:

\section{It provides an avenue for the continuity of the Programme}

Programme planning should be well planned and written down. Programmes should be written, for when there is a change of extension workers in an area, the lack of a written programme deprives the new man of the experience and local knowledge as acquired by his predecessor. Therefore, a good programme planning should be written down and documented for the continuity of the programme against an unforeseeable occurrence.

\section{It provides basis for co-operation}

A written extension programme helps other organizations like community development, home-crafts and health workers, staff of the farmers' marketing and co-operative, local government among others in rural development to understand and support extension activities.

\section{Concentration on the needs and interests of their client groups}

It helps the extension agents to base their activities on the needs and interests of their farmers. Farmers will only adopt an innovation that is not repugnant to their needs and interests. Therefore, programme planning should be based on the interests and needs of the people consuming it and not the other way round. 
Programme planning gives room for clear cut written objectives

Extension programme objectives should be clearly defined and recorded so that they can be given support by local leaders and others of influence. The extension workers cannot hope to convince leaders and farmers of the soundness of his programme objectives unless he examines jointly with them the facts, problems and possible alternative solution. Therefore, there is need to incorporate all the actors involved in programme during planning stage. It is easier to assess progress when there is a definite statement of extension aims and intensions. It serves as a public relation device, essentially making others to know what agricultural extension is doing, what problems do exist and how they are being solved. Programme planning helps extension workers to determine priorities of the various tasks. That is, first thing first. It represents a blue-print of needs in terms of time, resources and personnel. Programme planning gives room for knowing the specific resources required to work done at the various segments of an extension organization and Programme planning provides basis for financial appropriation and budgeting.

\section{Various approaches to Programme Planning/Development}

In planning extension programme, the agent should balance national and local requirements. That is everybody should be carried along both at national and local level provided the person has a contribution to the programme. However, he should take note of national objectives and also work with local people so that the programme that emerges is theirs, and reflects their needs. This local involvement in planning is an important part of the educational process of extension. It stimulates a close analysis of farming problems and helps to build up motivation and selfconfidence in using local resources to tackle them.

In some countries, agents work with formal, local-level committees when planning extension programmes. However this local involvement is achieved, the agent must take care that those who are involved can really represent the views and interests of all groups in the area. Committees often contain a high proportion of the more progressive, larger-scale farmers and are therefore inclined to promote programmes that fit the interests of these particular groups. In view of these, it is pertinent to know that whatever particular approaches/procedures for programme planning are laid down by the extension organization, five distinct stages can be identified and this will then lead to a review of the situation and the planning of a new programme, which should build on the achievements and learn from the failures of the previous one.

The five stages in programme planning are situation analysis, setting objectives, implementation stage and evaluation. However, the different stages of extension programme planning are interrelated and the planning does not always proceed neatly from one stage to another. Provisional objectives, for example, may be set during the situation analysis stage, but they may later be altered as new facts are collected and a critical analysis leads to full understanding of the situation. Objectives may have to be altered still further as unexpected difficulties arise while the programme is being implemented. However, it is useful for the agent to think of programme planning as involving these five activities, each of which will be considered in more detail, as each can be broken down into smaller steps.

\section{Situation Analysis}

Before an extension programme can be draw up, the existing situation must first be analyzed. Farming problems and their causes must be understood and the natural, human and other resources of the area identified. This stage involves three activities.

\section{Collecting facts}

There is a good deal of information that the agent will need about the people in the area, their farming systems, natural resources and the facilities available for local development. The agent will need information in order to have a good understanding of the situation with which he is dealing, for example, on social structure and local culture, farming systems, education and literacy levels, size of farms, local channels of communication, transport facilities, local credit systems, marketing, health and nutrition levels, and crops and livestock.

These facts can be collected from a variety of sources. Reports of soil classification and land-use surveys, farm management studies, social surveys and previous programmes can provide a lot of useful background information. If the agent keeps good records of the farms in his area, he will have at his fingertips much of the information he needs. He can also obtain a lot of his information from farmers and local leaders. At public meetings, in group discussions and in contact with individual farmers, the agent should listen, ask questions and gradually build up a full understanding of the social, agricultural and economic features of the area.

Detailed social and economic surveys require complex questionnaires and statistical analysis, and are best left to professional researchers. But simple questionnaires can be used in this fact-finding exercise and it is helpful if the extension organization provides a standard list of questions or facts as a guide to the agent. One way in which farmers can be brought into the planning process at this early stage is for them to do some of the factfinding themselves, using simple check-lists and questionnaires, for example, to catalogue natural resources in the area.

\section{Analysing facts}

Facts do not speak for themselves. It is necessary to ask why things happen in the way they do. If farmers report that yields have declined in recent years, the agent must look for other information that would suggest an explanation. Is it because of low rainfall, declining soil fertility, or poor seed? The agent must also separate fact from opinion and guesswork. He may obtain conflicting information from two different sources, and must judge which is the more reliable.

\section{Identifying problems and potential}

It should now be possible to decide what the main problems facing farmers in the area are, and what potential there is for 
agricultural improvement. This is where the agent's technical knowledge becomes important. Farmers may know what their problems are, but the agent can bring his own perception of local problems based on a more scientific understanding of farming He will be able to explain problems more fully and relate them to processes which farmers may not realize are in any way connected. Because of his training and experience, he will also have more suggestions to make about how the resources of the area could be used more productively.

Throughout the situation analysis, the agent should avoid either, relying totally on his own expertise when interpreting facts and identifying problems, or leaving it entirely up to farmers to define local needs and possibilities for change. It should be a joint effort, with agents and farmers bringing their own experience and knowledge together to reach a full understanding. If farmers are not fully involved in these activities, the agent runs the risk of misinterpreting facts, wasting time in analysis and, almost certainly, of failing to gain the full support of farmers for the programme. A full situation analysis is not needed every year. The basic facts about the area and the people will, in most situations, not change very much from year to year. However, the agent should review basic information each year and decide which parts of it need to be updated.

\section{Setting Objectives}

Once the existing situation has been analyzed, decisions can be made about the changes that should be brought about through an extension programme. The key questions are how will local problems be solved and how will local potential be developed. Solutions will require clear, realistic objectives which should be set in three stages.

\section{Finding solutions}

In looking for solutions to local problems, the agent should distinguish between technical solutions, involving improved inputs or simple changes in husbandry practice, and solutions which involve institutional changes, such as improved credit and marketing systems. Solutions involving institutional changes may require action by other agencies and at higher levels. While the agent should certainly suggest such solutions to those responsible, there may be little that can be done locally in isolation. The sources of ideas for developing an area's potential include: the agent's own technical knowledge, farmers and agents from other areas who have tackled similar problems successfully, applied research which tests new ideas under farm conditions, national priorities and directives and projects which make funds available for particular activities.

\section{Selecting solutions}

When selecting from among the range of solutions and possible improvements, agent and farmers should ensure that proposed solutions are: Acceptable to farmers in the area, technically sound and tested by research and experience elsewhere, consistent with national policy, and with the local activities of other agencies, feasible within the time and with the resources available to farmers and the extension service And within the scope of the agent's ability and job description. The agent may find that some problems will have no feasible or acceptable solution that can be implemented locally within the period of the extension programme. They may require legislation, action at other levels and by other agencies, or more research. The agent should lessen the effect of such problems where possible and act as a channel for putting forward the case for changes to those who have the power to make them.

\section{Stating objectives}

It should now be possible to state what the objectives of the extension programme are to be. But because his time and resources may be limited, the agent must decide which objectives have a higher priority than others. In doing so, he should consider national priorities and the size and distribution of the benefits that will arise from a given input of time and resources. Wherever possible, objectives should be expressed in terms of amounts and numbers, rather than general statements. "Establish two groups of dairy farmers who will share new equipment and market their produce jointly" and "Increase the acreage of improved rice varieties from 60 to 120 acres" are more useful objectives than "Improve dairy farming techniques" or "Increase the use of improved rice seed". They give the agent firm targets to work toward, and a standard against which the effectiveness of the programme can be judged at the end of the year. The objectives for an annual extension programme will state what should have been achieved by the end of the programme.

These statements can be broken down into intermediate steps to be taken during the year in order to achieve the programme objectives. Again, the agent will have to make choices, selecting the most appropriate steps from several possibilities. As the agent breaks down each programme objective into specific steps, he will in effect be preparing a schedule of extension activities for the programme period. He will decide what knowledge and skills the farmers will need; what additional technical information will be required from specialists and research workers; what extension methods should be used; and what resources and support he will need from his own and other agencies.

When the planning is completed for other programme objectives, the agent can compile all the plans into an overall annual work plan. He may find that he cannot possibly do everything that all the individual plans require, so some of the lower priority objectives may have to be dropped, or scaled down. The annual work plan does not specify what the agent will be doing on each day during the year, but it should indicate when each extension activity will begin and end, and what resources will be needed for each.

\section{Implementation}

To implement the programme, the agent carries out the activities specified in the work plan. His detailed monthly and weekly plans will take account of progress and problems encountered in previous months. For example, the timing of some activities may have to be changed, or additional method demonstrations may be planned if more farmers than expected want to take part. An extension 
programme should be flexible enough to allow the agent to respond to circumstances in this way.

\section{Evaluation}

The agent will be constantly reviewing and assessing his progress during the year. At the end of the year, a more thorough evaluation should be carried out in which the agent identifies how fully each objective has been achieved, and the reasons for any lack of progress. This evaluation, together with an up-dated situation analysis, provides the basis for planning the next year's programme. Evaluation is the process by which the effectiveness of extension is assessed.

It is more than simply finding out what happened; it involves passing judgment on what happened. Was the outcome of the programme good enough? Was it better or worse than expected? Could more have been achieved? Extension programmes are evaluated to

a) ascertain for the extension organization how well agents perform, so that their suitability for promotion may be assessed;

b) satisfy the government that public money spent on extension is being used effectively; and

c) Permit the agent to learn from what has happened. Evaluation is a waste of time unless the results have an influence on future extension decisions.

One approach to evaluation is to ask if the programme's objectives were achieved. This is an important first step and one which is made easier if the programme had clear, precise objectives. If the answer is no, then there is no real basis on which to make improvements in future programmes. It is important, therefore, to ask why things turned out in the way they did. Only when that question is answered can the agent learn from the past. Agents should, therefore, ask questions about the programme's results and inputs.

According to (www.programme panning/the main planning. $\mathrm{htm}$ ) there are eight (8) basic planning process that may be used for many different kinds of planning-developing strategy, or programme and project planning. These steps can be adapted to use for specific planning purposes. Your decision about what kind of planning process you need will tell you how much time you must set aside, who should be involved, how and at what point.

\section{Step 1 Preparing to plan- ensuring commitment}

It is important to prepare well for any planning process. As we noted in the detailed guidelines on the approach to planning in the section above, planning should not be seen as something you do before you start on the real work, but as part of " the real work" itself. It takes up time, energy and other resources. It plays a crucial role in laying the basis for effective ongoing thinking, action and achievement. We also noted that involvement and participation are of vital importance to effective planning processes. We need to prepare effectively for planning to ensure we get the kind of involvement and participation we need. We must actively build commitment to the planning process so that people are willing to give the time, energy and resources necessary for effective planning.

One of the mistakes many non-profit organizations make is to underestimate the amount of time and commitment necessary for effective planning. This commitment will need to come from staff and all other stakeholders whose participation we decide is necessary to enable successful implementation and results. The kinds of issues you need to discuss and decide here are: What kind of planning do we need to do? How much time should we give to each step? How much time and other resources will we need for the whole planning process? Do we need more information on past experience, achievements or the situation we are hoping to influence before we start the planning and, if so, who will get it, how will they get it, where and from whom? Who are our key stakeholders (don't forget the staff of your own organization)? How important is their involvement to the successful implementation of our plans? How important is it that each main stakeholder group understands and agrees to the planning decisions? How important and/or influential is each main stakeholder group? Whose needs, interests and concerns should be prioritized in the planning process? How useful or essential would their involvement be at each step in the planning process? What kind of involvement will be adequate for each key stakeholder in each step of the process? How will we get the commitment to the planning process we need from each key stakeholder? How should each stakeholder be prepared so that they can participate effectively? What information will they need beforehand?

Do we need a planning committee or group to ensure the process runs smoothly? When will the planning begin and what target dates should we set for the completion of each step? Who will facilitate each session? Who will keep and circulate a record of our discussions? How soon after each step must the record be circulated? What other tasks need to be done, by whom and by when (organizing venues, food, transport etc)? What other resources will we need (flip charts, overhead projectors, kokis, pens and paper, inputs, press tick, admin support for contacting people and circulating records of discussions etc)? Once you have made these decisions, built a commitment to participate and prepared everyone who must participate to do so effectively, you are ready to start the actual planning process.

\section{Step 2 Analyze the situation and needs}

This step involves collecting and analyzing information you will need to decide on a goal and a purpose that is: Relevant to your target community; Realistic in terms of what is possible and likely to make a difference; and The most effective and appropriate contribution given the current situation you want to change. More so, you will need enough information to enable you to answer the following questions through careful analysis: What are the major problems faced by our target community? Which of these is the key or central problem or issue? What are the causes and effects of this problem? Can we realistically hope to make a significant contribution to addressing this problem? 
How does this problem or issue affect our primary stakeholders? How do they see it? What are their concerns and interests in relation to the problem or issue? Do key stakeholders stand to gain or lose from our taking up this problem or issue? How does this affect our work and planning? What experience have we had so far that is relevant to this problem or issue and what can we learn from it? And what can our organization realistically expect to achieve? What resources and capacity are available to us inside and outside our organization? What does this mean for our planning? This step in the planning process lays the basis for the rest of the planning process.

The process of building a deeper understanding of the problem, the situation, and your organization is important for both the staff of your organization and your target community. It lays the basis for shared understanding, more effective decisions and a commitment to strategic action. You will draw on the thinking done at this step as the basis for your decisions in all the later steps. In the next steps, you will make important decisions when you choose: Your goal - a clear statement of the long term change you would like to see. This is usually not something you can achieve alone, but is an important change that will improve the lives of your target community. This is the long-term goal your organization decides it must contribute to bringing about. Clarifying this broad goal helps to keep the rest of your planning focused on what will make a real contribution to change, even if it is only a part of a bigger and longer-term change. Your purpose- your organization's contribution to the goal- this should be a clear statement of what your organization commits itself to achieve. This must be something that will make an important contribution to the achievement of the goal. But, it must also be something your organization can realistically achieve on its own.

Your objectives - specific statements of what has to be achieved [results] by your organization to reach the organization's purpose and your activities- clear decisions about who will do what and by when in order to achieve each objective. Each of these decisions builds on your earlier decisions, but all of them depend on how well you have done the analysis. The analysis helps you ensure that your goal, purpose, objectives and activities are relevant, useful and realistic. The next step is to decide on a goal and purpose that is relevant to the needs of your target group but also realistic in the context. The needs analysis will assist you to ensure that this decision about the future situation you wish to bring about is based on a deeper understanding of the problem and its causes and effects.

\section{Step 3 Prioritize and select the goal and Purpose}

Deciding on a goal is important because this tells you what change in people's lives you hope to contribute to bringing about. A goal is a clear statement of the future situation you would like to come about. Goals are usually longer-term aims that your organization cannot hope to bring about alone but will make a significant contribution to helping bring about. They tell us why we do what we do. Goals are also the final basis on which you evaluate what you have achieved. When you are developing a strategy for your organization, this is a very important strategic decision. It is the vision of what you would like to see that will guide everything else you do.

All further programme or project planning must be relevant to helping bring this about. Once we know what your goal is, you need to decide on the purpose of your organization - why do we exist and what contribution will we make to achieve the goal? The purpose is a clear and concrete statement of what you undertake to achieve. The purpose should be something you can realistically achieve as a result of your work. Agreeing a purpose is making a clear commitment to achieving this result. However, If you are developing an organizational strategy, the purpose explains why your organization exists, its mission. In programme or project plans, the purpose must state what that programme or project will achieve. This should be based on the overall strategic goal and purpose of the organization as a whole as agreed in the organization's strategy.

In this case, you will use your needs analysis to decide: What is the future situation you will contribute to bringing about? What is the most relevant goal? What is the most clear and concrete way of stating this goal? What you can achieve (as an organization, programme or project) that will make the most significant and useful contribution to achieving the goal you have agreed on? What is the most relevant but also most realistic purpose (for our organization, programme or project)? What external conditions will need to exist for you to achieve your goal and purpose? How important are these to your success. Can you influence them, and if so how (you will need to include this in your later planning)? If they are important, unlikely to come about but you can't influence them, does this mean the goal and purpose are unrealistic? It is important to remember that you are making choices when you decide on a goal and purpose. These choices need to be strategic (carefully selected from the alternatives as the most useful) as they will affect all of your further planning. They also need to be as clear as possible so that they are a record of agreement that can guide your further decisions and actions and be used as a basis for assessing what you are achieving. In the next step you will be deciding on clear specific objectives that will enable you to achieve your goal.

\section{Step 4 Develop Clear Specific Objectives}

Objectives are concrete results you need to achieve in order to reach the purpose. Objectives should be as clear and specific as possible. They should state the result you aim to achieve, not what you will do to achieve it. This helps you to focus on what the effect of your work should be, not only on your activities. It also allows you to evaluate what were achieved in terms of changes in the real world, not just what you did. Objectives should be more specific and concrete than your purpose and should be relevant to achieving your purpose.

In this step you will use your needs analysis and your agreed goal and purpose to decide: What specific results are needed to achieve your purpose? The needs analysis included an analysis of the causes and effects of the problem-do the causes you identified give you an idea of what must change in order to achieve your purpose? 
What objectives will we have to achieve to achieve the purpose? Is it possible to make your objectives more specific by stating by when they should be achieved, who should benefit, how many or much must be achieved and how well? Can you realistically achieve these results? If not, can you improve your capacity to achieve them by, for example, building alliances and improving your organizational capacity? Do you need to set objectives to take account of these things? (If you can't improve your capacity to achieve the results that are necessary to achieve the purpose, you will need to go back and make the purpose more realistic).

What external conditions will need to exist for you to achieve your objectives effectively? How likely are they to happen? Can you do anything to influence the situation so that these conditions exist? (You will need to include these things as either objectives or as part of your plans for implementing your strategy). If they are important and unlikely to exist, but you can't influence them, are your objectives realistic? Once you have clear, specific and agreed objectives, you are ready to begin planning the actions you will take to achieve them. The goal, purpose and objectives are the foundations of this process. You will need to decide on the best strategy for achieving each objective.

\section{Step 5 Identify Alternative Strategies and Select the Most Effective Strategy}

This step involves trying to find the best way of achieving your objectives. Strategy is the choice we make about the best approach to getting something done. This is a very important step. It enables us to avoid just assuming that there is a right way of getting something done and forces us to look at alternatives that we may not have considered properly before. This is very important if you want to find new and more effective ways of doing things. Just doing things the way you always do them, may not be strategic. You won't know unless you deliberately think of other options and test them out with open minds. The biggest mistakes and waste in development work are made by organizations that do not keep testing their thinking to come up with better and more relevant strategies.

In this step, you will use the deeper understanding of the problem and stakeholder needs developed in your needs analysis to decide: What are the alternative ways you could use to achieve each objective? What criteria will you use to assess each strategy (e.g. relevance, realistic etc) in order to choose the most effective and realistic alternative? Based on these criteria, what is the most effective strategy for achieving each objective? What external conditions will need to exist for you to effectively implement each strategy? How important are they to your strategy succeeding? How likely are they to happen? Can you do anything to influence the situation so that these conditions exist? (You will need to include these things as part of your strategy). If they are important and unlikely to exist, but you can't influence them, is your strategy realistic? What resources will be needed? Is this realistic? Once you have agreed realistic and effective strategies for achieving each of your objectives, you are ready to start planning to implement them by developing activity plans.

\section{Step 6 Plan implementation}

This step involves detailed planning about how you will implement the strategies you have decided on. You will use the decisions about the most effective strategy to achieve each objective to decide: What major activities will be needed to implement each strategy? Who will be responsible? By when should activities by completed? What deadlines should be set? What specific resources will be needed for the activities required to achieve each strategy? When these are done, you are now ready to finalize your plan by planning for evaluation. The plans you make in the next step about when you will evaluate, who will be involved and how you will collect the information you need, should then be added to the implementation plan you have just drawn up as part of the activities.

\section{Step 7 Plan for evaluation}

This step involves planning how you will evaluate your progress and what has been successfully achieved. This needs to be done at the planning stage so that it can guide implementation by ensuring a clear record of agreements about what successful achievement means. It helps to clarify the plans by making sure that everyone understands what you intend to achieve in the same way. It also ensures you have a clear and agreed basis for assessing what was actually achieved and your progress along the way. If you have followed the systematic approach to planning outlined in the earlier section, you will already have a very useful basis for monitoring your progress and evaluating your achievements. In this stage you will use your needs analysis and overall plan to finally decide: What criteria or indicators you will use to evaluate progress and achievements in relation to your goal, purpose and specific objectives; When you will monitor progress and evaluate achievements; Where and from whom you will get the information you need; Who should be involved in monitoring progress and evaluating achievements; and How you will collect the information you will need. Once you have made these decisions, you have completed the planning process. Now, all that is needed is to summarize your plan in a neat, clear, easy-to-use form so that it is a useful record and guide for all those who will play a part in implementing it successfully.

\section{Step 8 Summaries your plan}

It is useful to summarize your plan as you go along and to keep circulating it to everyone along with a summary of the discussion after you complete each step. This will mean you have a clear record of your decisions at each step, which you can use in the next step. If you have done this all the way along and are using the Logical Framework Approach outlined in the section on how to plan systematically, you should have a useful record of your discussions that you can use to: Check your thinking and whether it all makes sense, Keep a clear record of decisions; Guide implementation; Monitor external conditions and make adjustments if your assumptions do not prove to be accurate; Explain your planning to donors or others whose assistance and support you decide to request; Evaluate progress and achievements; and check your previous thinking, when you start the next planning process, and improve it based on the learning you have done in the implementation and evaluation phases. 
How to ensure planning is useful and contributes to effective results

There are six main issues that are important to remember about how planning is done. These will help you make sure your planning meets the challenges outlined above, avoids common problems and that your plans are useful and effective.

1) Planning and evaluation must be participative. Everyone who must make a key contribution to the work of the organization should be included. There are two key reasons for this. Firstly, it enables you to draw on different ideas and experience to make better decisions. Secondly, it allows you to build commitment to these decisions by including all those who will need to contribute to the successful implementation of the planning decisions. Participation will ensure that everyone fully understands the strategy and plans and are committed to achieving the decisions that have been made. You will need to identify and analyze all key stakeholders that can affect whether you achieve your purpose and decide whether and how they should be included.

2) Planning and evaluation must be systematic. You have to ensure you have thought through and agreed on all key issues before moving on to the next step. For example, you need to be clear about the results you intend to achieve before you start making decisions about what action you will take. Non-profit organizations exist to make a difference to society, not just to do things. Everything you do must be relevant to the results you intend to achieve. You may also sometimes need to move back to previous steps in the planning process, if the later planning suggests you need to rethink some earlier decisions. For example, you may realize that the action you would need to be able to take is not realistic. This may lead you to decide that you will have to alter your decisions about what results you can realistically expect to achieve. Effective planning seldom moves in one straight line but this does not mean it should not be systematic.

3) All planning should be strategic. This means that you should use your planning processes to find the best ways of making a difference and the best approach to doing this. All possible alternatives should be examined, not just the ones we are comfortable with. Effective planning lays the basis for ongoing strategic thinking and action from everyone who will contribute to achieving your organization's purpose. All decisions and action and all use of resources need to make the most strategic contribution to achieving the purpose you have agreed on.

4) Planning must include agreements about how and when you will evaluate progress and achievements. You will need to make decisions about what you will use to tell you if you are making progress or have achieved your purpose. You will also need to agree on where you will get the information and when you will evaluate, how and who should be involved.

5) Effective planning requires a major commitment from everyone in the organization. Planning can take time; it can seem messy and frustrating. But, studies show that one of the key factors in effective planning is how committed the organization and the people are to the planning process. A further key factor here is that enough time should be given to planning effectively - it will save you time later.

6) Planning and evaluation must be thought of as a cycle of learning and improvement, not a straight line from A to B. We must continually evaluate what we are achieving and use our learning to develop more effective ways of achieving our goals.

\section{Important things to know about planning and evaluation}

Planning and evaluation make a simple question of working out how we get from where we are now to where we want to be. It seems as simple as using a road map to move from one place to another. That is fine if you know exactly where you are and where you want to be and you have a reliable map of the roads you must take to get there. If you have these things, an adequate means of transport and you use your map, you can simply set off. Although knowing where we are, where we need to be and how to get there are the basic things we need to know to plan effectively (Table 2 \& $3)$.

\section{Conclusion and Recommendations}

The primary goal of extension programme planner is to raise productivity, through increased utilization of recommended innovation among farmers. Unplanned activities can lead to low productivity, disturbance and frustration at work. Planning in extension involves determining "where to go" and "how" to get there in terms of human and material resources as well as good coordination. One key principle in planning is involvement of the clientele and other stakeholders in programme planning for effective result to be achieved.

Development in agriculture is seen as synonymous with rural development because since about $90 \%$ of rural dwellers are engaged in agricultural practices as their major source of income, this implies that rural areas cannot attain development without its agriculture being developed. However, agricultural development is not only increasing the productivity of the farmers alone but also it considers all the social welfare needed as a human being. Therefore, democracy is said to be incompetent once its dividend is not feasible and perceived by the rural people. In the light of the above, the writer used the available literatures to review the following issues; Agricultural extension programme, programme, who is a programmar, planning resources, programme planning in extension, importance of programme planning in extension, project, rural development, monitoring and evaluation in extension, similiarities between monitoring and evaluation, difference between monitoring and evaluation, monitoring indication, the main players in evaluation, the four elements of evaluation ,the various approach used in programme planning/development, work plan and calendar of work in extension programme. 
Table 2: Plan of Work.

\begin{tabular}{|c|c|c|c|c|c|}
\hline Activity & $\begin{array}{l}\text { Required } \\
\text { Resources \& } \\
\text { Source }\end{array}$ & (When) Date/Time & (Where) Place & $\begin{array}{l}\text { (Whom) Persons } \\
\text { Concerned }\end{array}$ & Purpose (Result Expected) \\
\hline Extension campaign & & $\begin{array}{l}\text { April } 15 \text { to August } 25 \text {, } \\
2017 \text { (1 week) 5.30- } \\
6.30 \text { pm daily }\end{array}$ & $\begin{array}{c}\text { (Ayamelum L. Govt. Area) } \\
\text { Omor town (1 evening) } \\
\text { Aturia (1 evening), } \\
\text { Akanato (1 evening) } \\
\text { Orenja ( } 1 \text { evening) } \\
\text { Amikwe (1 evening) } \\
\text { Igbakwu (1 evening) }\end{array}$ & $\begin{array}{l}\text { Rice growing farmers } \\
\text { in Ayamelum L.G.A. } \\
\text { Extension Officers } \\
\text { Mr. Udemezue JC, Mr. } \\
\text { Okonkwo JC Mrs. Ede } \\
\text { ON. }\end{array}$ & $\begin{array}{l}\text { To create awareness on } \\
\text { the need to use wet-bed } \\
\text { method to prepare FARO } \\
44 \text { rice seedlings, the need } \\
\text { to improve quality and } \\
\text { quantity of rice production } \\
\text { through the above method. }\end{array}$ \\
\hline Farmers meeting & & $\begin{array}{c}\text { October 22, } 2009 \\
5.30-6.15 \mathrm{p}\end{array}$ & $\begin{array}{l}\text { Omor town hall. } \\
\text { (Ayamelum LGA) }\end{array}$ & $\begin{array}{l}\text { (a) Rice growing } \\
\text { farmers in Ayamelum } \\
\text { LGA; (b) Extension } \\
\text { officers; (Mr. } \\
\text { Udemezue JC, Mr. } \\
\text { Okonkwo JC Mrs. Ede } \\
\text { ON. }\end{array}$ & $\begin{array}{l}\text { To convince the farmers } \\
\text { that wet-bed method is } \\
\text { better than their traditional } \\
\text { method of raising seedlings. }\end{array}$ \\
\hline $\begin{array}{l}\text { Repetition of } \\
\text { Campaign }\end{array}$ & & $\begin{array}{c}\text { October } 28 \text { to October } \\
30,2017 \\
5.30-6.30 \mathrm{pm} \text { daily }\end{array}$ & $\begin{array}{l}\text { Run through in the above } \\
\text { specified villages }\end{array}$ & $\begin{array}{c}\text { (a) Rice growing } \\
\text { farmers in Ayamelu } \\
\text { LGA. } \\
\text { (b) Extension officers: } \\
\text { (Mr. } \\
\text { Udemezue JC, Mr. } \\
\text { Okonkwo JC, Mrs. Ede } \\
\text { ON. }\end{array}$ & $\begin{array}{l}\text { To intensify campaign so } \\
\text { that farmers can come for } \\
\text { the training. }\end{array}$ \\
\hline Meeting & & $\begin{array}{c}\text { 10/31/2017 5.30- } \\
\text { 6.30p.m. }\end{array}$ & $\begin{array}{l}\text { omor town Hall, } \\
\text { Ayamelum LGA }\end{array}$ & $\begin{array}{l}\text { Rice growing farmers. } \\
\text { Extension officers: } 1 . \\
\text { Mrs. Egeonu } \\
\text { 2. Mr. Okoli } \\
\text { 3. Mr. C Uduma }\end{array}$ & \\
\hline Training programme & & $\begin{array}{l}\text { Nov. 5- Nov. } 10,2017 \\
5.30-6.30 \text { p.m. daily }\end{array}$ & $\begin{array}{l}\text { Ifite ogwarri village in } \\
\text { Ayamelum Loc. Govt. Area }\end{array}$ & -do- & $\begin{array}{l}\text { Farmers to be taught how to } \\
\text { prepare wet- beds }\end{array}$ \\
\hline $\begin{array}{c}\text { Method } \\
\text { demonstration } \\
\text { (learning by doing) }\end{array}$ & & $\begin{array}{l}\text { Nov. } 12-17,20174.30- \\
\quad 6.30 \text { p.m. daily }\end{array}$ & $\begin{array}{c}\text { Mr. F. Madu"s farm } \\
\text { at Okputa (selected } \\
\text { in a meeting held \& } \\
\text { unanimously agreed } \\
\text { upon). }\end{array}$ & “ & $\begin{array}{l}\text { To teach steps (by method } \\
\text { demonstration) in soaking. }\end{array}$ \\
\hline $\begin{array}{l}\text { Method } \\
\text { demonstration/ } \\
\text { training }\end{array}$ & & $\begin{array}{l}\text { Nov. } 26-30,20174.30- \\
\quad 6.30 \text { p.m. Daily }\end{array}$ & Okputa & “ & $\begin{array}{l}\text { To teach by method } \\
\text { demonstration) sowing } \\
\text { of FARO 44rice variety on } \\
\text { prepared wet-bed }\end{array}$ \\
\hline $\begin{array}{c}\text { Method } \\
\text { demonstration/ } \\
\text { training } \\
\text { programme/ } \\
\text { learning by doing. }\end{array}$ & & $\begin{array}{l}\text { Dec. } 3 \text { - 7, } 20174.30- \\
\quad 6.30 \text { p.m. daily }\end{array}$ & - do- & “ & $\begin{array}{c}\text { To teach how to irrigate } \\
\text { seed-beds }\end{array}$ \\
\hline $\begin{array}{l}\text { Brief meeting } \\
\text { followed by method } \\
\text { Demonstration }\end{array}$ & & $\begin{array}{l}\text { Dec. } 12,20174.30 \\
-6.30 \text { p. m. daily }\end{array}$ & “ & “ & $\begin{array}{l}\text { Farmers to be reminded on } \\
\text { irrigation of seed beds. }\end{array}$ \\
\hline $\begin{array}{l}\text { Lectures/method } \\
\text { demonstration/ } \\
\text { learning by doing. }\end{array}$ & & $\begin{array}{l}\text { Dec. } 27 \text { - 28, } 2017 \text { 4;30 } \\
\text { - 6;30 p.m. Daily }\end{array}$ & “ & “ & $\begin{array}{l}\text { Farmers to know how to } \\
\text { lift seedlings from the seed } \\
\text { beds to the field without } \\
\text { damaging the roots. }\end{array}$ \\
\hline
\end{tabular}


Table 3: Calendar of Work (2017).

\begin{tabular}{|c|c|}
\hline Months & Operations \\
\hline \multirow{2}{*}{$3^{\text {rd }}$ week in January } & $\begin{array}{l}\text { Extension campaign begins in order to explain to the farmers in Ayamelum Local Government Area the need for } \\
\text { improving rice production and quality of rice by the use of wet-bed method. }\end{array}$ \\
\hline & $\begin{array}{c}\text { Meeting to help farmers in Aturia village understands that the wet- bed method is better than the traditional } \\
\text { methods. }\end{array}$ \\
\hline \multirow{2}{*}{$4^{\text {th }}$ week in January } & Campaign to be intensified for more farmers to come for the training. \\
\hline & Meeting for selecting and preparing the land to be used in teaching the farmers. \\
\hline $1^{\text {st }}$ week in February & Farmers to be trained on how to prepare the wet-beds. Method demonstration to be used. \\
\hline $2^{\text {nd }}$ week in February & $\begin{array}{c}\text { With the use of method demonstration, teach the farmers the steps in soaking and incubation of the seeds before } \\
\text { sowing. }\end{array}$ \\
\hline $4^{\text {th }}$ week in February & Farmers to be taught how to sow rice seeds into the wet-bed. \\
\hline \multirow{3}{*}{$1^{\text {st }}$ Week in March } & Farmers are taught how to irrigate the seed beds gradually to a depth of about $1 \mathrm{~cm}$. \\
\hline & Farmers to be reminded of the need to irrigate the seed beds continuously to control weeds. \\
\hline & $\begin{array}{c}\text { Farmers to learn how to drain occasionally to improve aeration of the soil and encourage the production of } \\
\text { vigorous seedlings with short roots. }\end{array}$ \\
\hline \multirow{4}{*}{$2^{\text {nd }}$ week in March } & Teach farmers how to apply the insecticide: \\
\hline & a) Dithane M 45 (w.p. at 20 grams in one litre of water). \\
\hline & b) Benlate EC at $1-2 \mathrm{~kg} / \mathrm{ha}$ \\
\hline & c) Fertilizer N.P.K. 15. 15. 15 \\
\hline \multirow{2}{*}{$3^{\text {rd }}$ Week in March } & 1.Teach farmers how to lift seedlings from the wet-bed without causing damage to the roots \\
\hline & 2.Farmers to learn how to transplant the seedlings and recommended spacing to be taught. \\
\hline
\end{tabular}

This paper recommends that the extension workers who are the key players in information dissemination to farmers should know the various approach used in programme planning and development. Government in all sectors should organize work shop for workers as regards to progamme planning/development just to make work effective and functional, the knowledge of monitoring and evaluation should be kept abreast with the extension workers and other government staff for effective delivering job. Government at all levels should intensify effort for effective monitoring and evaluation of all the projects assigned to a location. Sanctions should be imposed on any contractor/extension agent who fails to deliver project assigned to him/her for the benefit of the masses. Remunerations and incentives should be given to extension workers in order to discharge their project diligently. More programmes should also be assigned to the various communities in Nigeria for rural development. Extension agent should make use of work plan and calendar of work in teaching farmers in order to get project well done.

\section{References}

1. Udemezue JC, Oforle EO, Maduekwe VC (2017) Political Diversifications, Corruptions and Agricultural Dwindling in Nigeria: A Paradigm Shift in
Agricultural Sectors. International Journal of Interdisciplinary Research and Innovations 5(2): 16-28.

2. Nwachukwu I (2008) Planning and Evaluation of Agricultural and Rural Development Projects. Lamb Hourse Publishers pp. 1-71.

3. Maddock N, Wilson FA (1994) Projects Design for Agricultural Development. Avebury publishers, England.

4. Longman, Dictionary of Contemporary English (2007).

5. Ajayi AR (2005) Programme Planning, Monitoring and Evaluation in Agricultural Extension. Agricultural Extension Society of Nigeria, $\left(1^{\text {st }}\right.$ edn), p. 38-57.

6. Ekpere JA (1984) Extension Programme Development and evaluation Monograph, Department of Agricultural Extension and Rural Development, University of Ibadan, "Ibadan, Oyo State, Nigeria.

7. Freeman HE, Rossi PH, Wright SR (1979) Evaluating Social Projects in Developing Countries. Organization for Economic Cooperation and Development, pp. 239.

8. Groot AE, Stuist JPM, Boon CAM (1995) Changing Perspectives on Monitoring and Evaluation in Agricultural Extension in Africa. Proceedings of an International Workshop, Cameroon, pp. 121-132.

9. William Trochim MK (2006) The planning-evaluation cycle. Web center for social research methods.

10. Bradfield DJ (1988) Guide to Extension Training. FAO Rome, p. 15-16. 

(c) (i) Creative Commons Attribution 4.0

For possible submissions Click Here

Submit Article
MCDA $\begin{gathered}\text { Modern concepts } \\ \text { a Developments } \\ \text { in Agronomy }\end{gathered}$

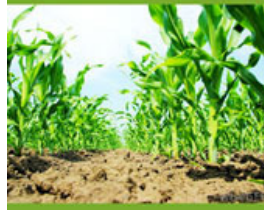

Modern Concepts \& Developments in Agronomy

\section{Benefits of Publishing with us}

- High-level peer review and editorial services

- Freely accessible online immediately upon publication

- Authors retain the copyright to their work

- Licensing it under a Creative Commons license

- Visibility through different online platforms 